\title{
Cationic Ring-Opening Isomerization Polymerization of Bicyclo Ortho Esters Initiated by Carbon Black
}

\author{
Norio TsuboKawa, Shingo OHShima, Yasuo Sone, \\ and Takeshi ENDO* \\ Department of Applied Chemistry, Faculty of Engineering, \\ Niigata University, \\ 8050, 2-nocho Ikarashi, Niigata 950-21, Japan \\ * Research Laboratory of Resources Utilization, \\ Tokyo Institute of Technology, \\ Nagatsuta, Midori-ku, Yokohama 227, Japan
}

(Received December 19, 1987)

\begin{abstract}
The cationic ring-opening isomerization polymerization of bicyclo ortho esters (BOE) such as 1-phenyl-4-ethyl-2,6,7-trioxabicyclo[2.2.2]octane and 1,4-diethyl-2,6,7-trioxabicyclo[2.2.2] octane initiated by carbon black was investigated. The polymerization scarcely proceeded in the absence of carbon black. But in the presence of channel black having carboxyl groups, the polymerization of $\mathrm{BOE}$ was initiated at $130^{\circ} \mathrm{C}$ to give a polyether containing an ester group in the side chain. The initiating ability of carbon black increased with increase in its carboxyl group content. Furnace black having no carboxyl group was unable to initiate the polymerization. Based on these results, it was concluded that the carboxyl group on carbon black is capable of initiating the polymerization of BOE. During the polymerization, a part of the polymers formed was grafted onto carbon black via the termination of growing polymer chain. Furthermore, the ring-opening isomerization polymerization of BOE was found to be initiated by an acylium perchlorate group introduced onto the carbon black surface. The polyether containing ester group in side chain was effectively grafted from carbon black, because the propagation of the polymer proceeded from the acylium perchlorate group on carbon black.

KEY WORDS Carbon Black / Cationic Initiator / Ring-Opening Isomerization Polymerization / Carboxyl Group / Acylium Perchlorate Group / Bicyclo Ortho Esters / Polyether / Grafting /
\end{abstract}

We reported that carbon black is capable of initiating the cationic polymerization of $\mathrm{N}$ vinylcarbazole, ${ }^{1}$ vinyl ethers, ${ }^{2} \quad \alpha$-methylstyrene, ${ }^{3}$ and $N$-vinyl-2-pyrrolidone. ${ }^{4}$ During the polymerization, the polymers formed were grafted onto carbon black via the termination of growing polymer chain. It was pointed out that the acidic sites, especially carboxyl groups, on the carbon black surface play important roles in cationic initiation and grafting. ${ }^{5}$ In the preceding paper, it was demonstrated that carbon black has ability to initiate the cationic ring-opening isomerization polymerization of spiro ortho esters ${ }^{6}$ and to crosslink polyfunctional spiro ortho ester resins. $^{7}$

Furthermore, we reported that carbon black containing acylium perchlorate groups is capable of initiating cationic polymerization of styrene $^{8}$ and cationic ring-opening polymerization of lactones, ${ }^{9}$ cyclic ethers, ${ }^{10}$ and cyclic formals. ${ }^{11}$ In such grafting reactions, the polymerization is initiated by the acylium perchlorate group on the carbon black surface and a polymer is grafted from carbon black.

It has been reported that the ring-opening isomerization polymerization of bicyclo ortho esters (BOE) is initiated by a cationic catalyst 
such as boron trifluoride etherate to give a polyether containing ester groups in the side chains above $70^{\circ} \mathrm{C}$ and that $\mathrm{BOE}$ is polymerized without shrinkage or with slight expansion. $^{12-14}$

In the present paper, we report the cationic ring-opening isomerization polymerization of BOE initiated by the carboxyl and acylium perchlorate groups on the carbon black surface. Futhermore, the mechanism of the initiation and grafting of polymers onto or from carbon black is discussed.

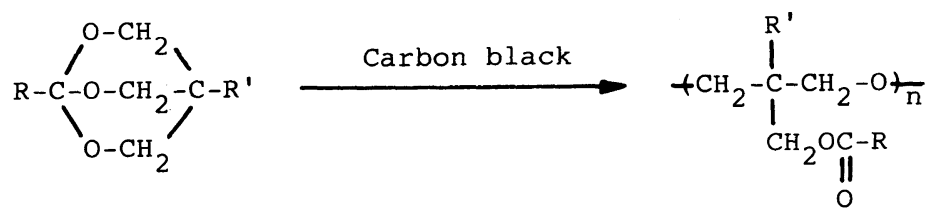

I: $\mathrm{R}=\mathrm{Ph}, \mathrm{R}^{\prime}=\mathrm{Et}$

II: $\mathbf{R}=\mathrm{R}^{\prime}=\mathrm{Et}$

\section{EXPERIMENTAL}

\section{Materials}

Furnace black Philblack O (Philips Petroleum Co.,) was extracted with benzene before use to remove resinous substances present on the surface. Channel blacks FW 200 (Degussa A.G.), Carbolac 1 (Cabot Corp.), and Neospectra II (Columbian Carbon Co.,) were used without extraction because they contain no resinous substances. The BET specific surface area, $\mathrm{pH}$, and the content of carboxyl $(\mathrm{COOH})$, phenolic hydroxyl $(\mathrm{OH})$, and quinonic oxygen $(\mathrm{C}=\mathrm{O})$ group are shown in Table $I$.

1-Phenyl-4-ethyl-2,6,7-trioxabicyclo[2.2.2]octane (I) and 1,4-diethyl-2,6,7-trioxabicyclo[2.2.2] octane (II) were prepared by reactions of the corresponding triol and orthocarboxylic ester with $p$-toluenesulfonic acid as a catalyst according to a method from the literature. $^{12,14}$

Guaranteed-reagent grade silver perchlorate obtained from Kojima Chemical was dried at $120^{\circ} \mathrm{C}$ before use. All other reagents and solvents were purified by the usual methods.

\section{Preparation of Treated Carbon Black}

In order to block the carboxyl group on its surface, carbon black was treated with aqueous solution of potassium hydroxide. ${ }^{15}$ Both carboxyl and phenolic hydroxyl group were blocked by methylation with diazomethane. ${ }^{16}$ These reaction procedures are described in detail in previous paper. ${ }^{6}$

Carboxyl groups were introduced on the surface of furnace black by oxidation with nitric acid. ${ }^{17}$ The treatment was carried out as follows. Into a $200 \mathrm{ml}$ flask equipped with a reflux condenser, $5.0 \mathrm{~g}$ of carbon black and $70 \mathrm{ml}$ of $35 \%$ nitric acid were charged. The mixture was stirred at $110^{\circ} \mathrm{C}$ for $5 \mathrm{~h}$. After the reaction, the carbon black was washed with water until the filtrate was neutral. The content of carboxyl group was determined to be $0.15 \mathrm{meq}^{-1}$ by the titration with an aqueous solution of sodium bicarbonate. ${ }^{18}$

\section{Polymerization Initiated by Carbon Black}

Into a $100 \mathrm{ml}$ flask containing $0.30 \mathrm{~g}$ of dry carbon black, $0.02 \mathrm{~mol}$ of freshly distilled BOE was added. The polymerization was conducted with stirring at $130^{\circ} \mathrm{C}$ under dry nitrogen. After the polymerization of $\mathbf{I}$, a viscous product was precipitated by the addition of $n$ pentane. The supernatant solution was removed by decantation. The precipitate was washed twice with $n$-pentane and dried in vacuo. When II was used as monomer, the 
Table I. Properties of carbon blacks used

\begin{tabular}{|c|c|c|c|c|c|}
\hline \multirow{2}{*}{ Carbon black } & \multirow{2}{*}{$\begin{array}{l}\text { BET surface } \\
\text { area } / \mathrm{m}^{2} \mathrm{~g}^{-1}\end{array}$} & \multirow{2}{*}{$\mathrm{pH}$} & $\mathrm{COOH}$ & \multirow{2}{*}{$\frac{\mathrm{OH}}{\mathrm{meq} \mathrm{g}^{-1}}$} & \multirow{2}{*}{$\frac{\mathrm{C}=\mathrm{O}}{\mathrm{meq} \mathrm{g}^{-1}}$} \\
\hline & & & meq $g^{-1}$ & & \\
\hline $\mathrm{FW} 200^{\mathrm{a}}$ & 460 & 2.0 & 0.61 & 0.10 & 1.42 \\
\hline Carbolac $1^{\mathrm{a}}$ & 839.2 & 3.0 & 0.54 & 0.16 & 1.14 \\
\hline Neospectra II $^{\mathrm{a}}$ & 906 & 3.0 & 0.40 & 0.24 & 0.92 \\
\hline Philblack $\mathrm{O}^{\mathrm{b}}$ & 79.6 & 8.7 & 0 & 0.02 & 0.18 \\
\hline
\end{tabular}

a Channel black. ${ }^{\mathrm{b}}$ Furnace black.

polymerization was terminated by the addition of a small amount of $N, N$-dimethylformamide and the monomer remaining was distilled off in vacuo below $70^{\circ} \mathrm{C}$. The conversion was determined by the following equation.

Conversion $(\%)$

$$
=\frac{\begin{array}{l}
\text { Weight of total_Weight of carbon } \\
\text { precipitate }(\mathrm{g})
\end{array}}{\text { Weight of monomer used }(\mathrm{g})} \times 100
$$

\section{Polymerization Initiated by Acylium Perchlo-} rate Group on Carbon Black

The introduction of acylium perchlorate groups on carbon black was carried out by reaction of carbon black containing acyl chloride group (CB-COCl) with silver perchlorate in nitrobenzene according to the method previously reported. ${ }^{8}$ A typical example is as follows. Into a $100 \mathrm{ml}$ flask that contained $0.30 \mathrm{~g}$ of $\mathrm{CB}-\mathrm{COCl}$, were added $0.20 \mathrm{~g}$ of silver perchlorate and $5.0 \mathrm{ml}$ of nitrobenzene and the mixture was stirred at room temperature for $2 \mathrm{~h}$. The content of acylium perchlorate group was determined to be $0.37 \mathrm{meq}^{-1}$ by titration. $^{19}$

After the above reaction, without isolation of the acylium perchlorate group-introduced carbon black, $0.02 \mathrm{~mol}$ of freshly distilled BOE was added and polymerization was conducted under dry nitrogen at $30-70^{\circ} \mathrm{C}$. Termination of the polymerization and isolation of products were carried out in the same manner as described above.

\section{Determination of Percentage of Grafting}

To separate the polymer-grafted carbon black from the reaction product containing ungrafted polymer, the product was extracted with chloroform using a Soxhlet extractor until no polymer could be detected in the extract. The percentage of grafting was determined from the following equation.

Percentage of grafting $(\%)$

$$
=\frac{\text { Weight of polymer grafted }(\mathrm{g})}{\text { Weight of carbon black used }(\mathrm{g})} \times 100
$$

\section{RESULTS AND DISCUSSION}

\section{Ring-Opening Isomerization Polymerization of I and II}

As mentioned above, a polyether containing an ester group in the side chain is obtained by polymerization of $\mathrm{BOE}$ by a cationic catalyst such as boron trifluoride etherate above $70^{\circ} \mathrm{C}^{12-14}$ But when the polymerization is carried out at $0^{\circ} \mathrm{C}$, only one ring of BOE opens to give a poly(orthoester). ${ }^{20}$

Therefore, the polymerization of BOE by carbon black and the structure of polymer formed were examined. The polymerizations of I and II were carried out at $130^{\circ} \mathrm{C}$ in the presence of $0.30 \mathrm{~g}$ of $\mathrm{FW} \mathrm{200.} \mathrm{The} \mathrm{results} \mathrm{are}$ shown in Figures 1 and 2. In the absence of FW 200, the conversions of I and II after 4 days were only $3 \%$ and $0 \%$, respectively. On contrast, in the presence of FW 200, the polymerizations of I and II proceeded. These results show that FW 200 has ability to initiate 


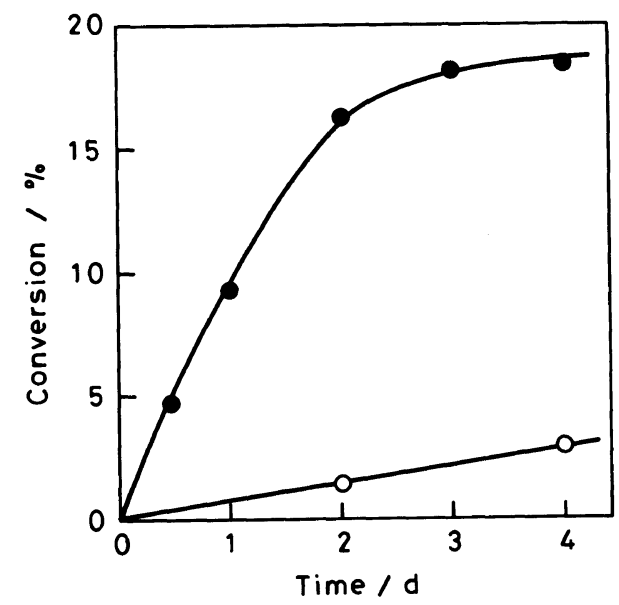

Figure 1. Ring-opening isomerization polymerization of BOE (I) initiated by FW 200 at $130^{\circ} \mathrm{C}$ : FW 200 , $0.30 \mathrm{~g}$; BOE (I), $0.02 \mathrm{~mol}$. (O), in the absence of carbon black; (O), in the presence of carbon black.

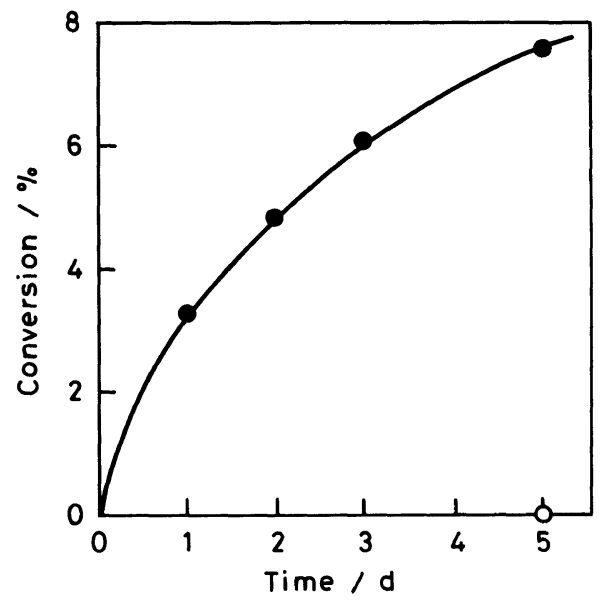

Figure 2. Ring-opening isomerization polymerization of BOE (II) initiated by FW 200 at $130^{\circ} \mathrm{C}$ : FW 200 , $0.30 \mathrm{~g}$; BOE (II), $0.02 \mathrm{~mol}$. (O), in the absence of carbon black; (O), in the presence of carbon black.

the ring-opening polymerization of $\mathrm{BOE}$. The obtained polymers were viscous liquids and identified as polyethers containing an ester group in the side chain by IR and NMR spectroscopy. ${ }^{12}$

On the other hand, the carbon black isolated after the polymerizations gave a stable colloidal dispersion when mixed with chloroform or tetrahydrofuran. This suggests that a part

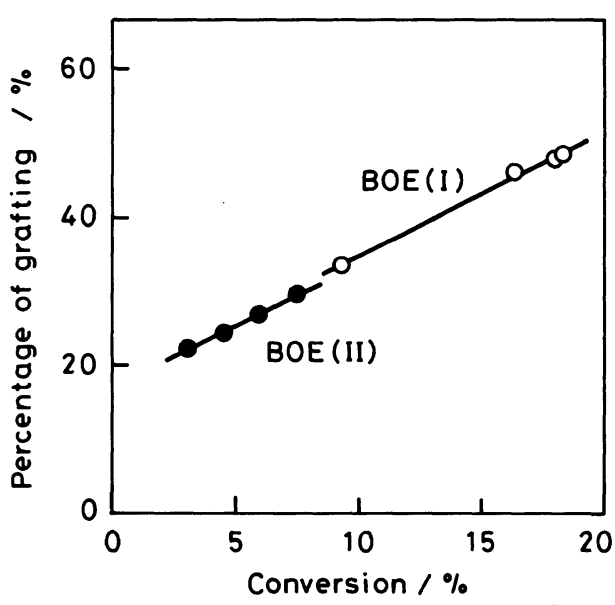

Figure 3. Grafting onto carbon black during the polymerization of I and II initiated by carbon black. Polymerization conditions are given in Figures 1 and 2.

of polymer formed was grafted onto the carbon black surface. The percentage of grafting onto carbon black was determined. The results are shown in Figure 3. Figure 3 shows that the polymer is grafted onto the carbon black surface during polymerization.

Accordingly, it is concluded that the ringopening isomerization polymerizations of I and II were initiated by carbon black and that the polymers formed were partly grafted onto the carbon black surface during polymerization.

\section{Functional Group on Carbon Black Responsible} for Initiation

The ring-opening isomerization polymerization of BOE initiated by carbon black was totally inhibited by the addition of a base such as triethylamine. This indicates that the polymerization proceeds though a cationic mechanism. Therefore, it is expected that the initiating site (functional group) is an acidic site, especially a carboxyl group.

To identify the initiating site on carbon black, the polymerization of I was carried out using various kinds of carbon blacks and the relationship between the initiating ability and the carboxyl group content of these carbon 
blacks was investigated. The results are summarized in Table II.

As mentioned above, the polymerization of I proceeded slightly even in the absence of carbon black. The conversion in the presence of FW 200, Carbolac 1, or Neospectra II, however, was much higher than that in the absence of carbon black. It is apparent that the initiating ability of polymerization by these carbon blacks and percentage of grafting increase with increase in the content of the carboxyl group on them.

Furnace black Philblack $O$, which contains no carboxyl group, was unable to initiate the polymerization of $\mathbf{I}$; i.e., the conversion in the presence of Philblack $\mathrm{O}$ was almost comparable to that in its absence. These results suggest that the carboxyl group on channel black is capable of initiating the polymerization of BOE and grafting of the polymer onto carbon black surface.

The initiating ability of carbon blacks treated with potassium hydroxide, diazomethane, and nitric acid was compared with that of untreated carbon black. The results are also shown in Table II. The carboxyl group on carbon black is easily neutralized by treatment with potassium hydroxide. It is well known that carboxyl and phenolic hydroxyl groups on carbon black are blocked by methylation with diazomethane. On the other hand, carboxyl group can be introduced on the surface of Philblack $\mathrm{O}$ by treatment with nitric acid.

As shown in Table II, FW 200 loses the ability to initiate the polymerization of $\mathbf{I}$ after treatment with potassium hydroxide or diazomethane. Philblack $\mathrm{O}$ treated with nitric acid has ability to initiate polymerization.

On the basis of the above results, it is concluded that the carboxyl groups on channel black have ability to initiate the cationic ringopening isomerization polymerization of BOE and a part of the polymer formed is grafted onto carbon black.

\section{Mechanism of Initiation and Grafting by Carboxyl Group on Carbon Black}

It is considered that the polymerization of BOE by the carboxyl group on carbon black is initiated by proton addition to one of the oxygen atoms of the monomer as in the case when using an ordinary cationic catalyst. The propagation of the polymer proceeds with carboxylate anion as the counter ion. The grafting of the polymer onto carbon black is due to neutralization of the propagating cation with a carboxylate anion. Ungrafted polymer will be formed by a chain transfer reaction with a trace of impurity $(\mathrm{BH})$ as shown in the reaction scheme:

Initiation and Propagation

$$
\begin{aligned}
& \mathrm{CB}-\mathrm{COO}^{-} \mathrm{H}^{+}+\stackrel{\mathrm{R}-\mathrm{C}-\mathrm{O}-\mathrm{CH}_{2}-\mathrm{C}-\mathrm{R}^{\prime}}{\mathrm{O}_{\mathrm{O}-\mathrm{CH}_{2}}-\mathrm{CH}_{2}} \longrightarrow\left[\stackrel{\mathrm{R}-\mathrm{C}-\mathrm{O}-\mathrm{CH}_{2}-\mathrm{C}^{\prime} \mathrm{R}^{\prime}}{{ }_{\mathrm{O}-\mathrm{CH}_{2}}^{\mathrm{H}}} \longrightarrow\right.
\end{aligned}
$$

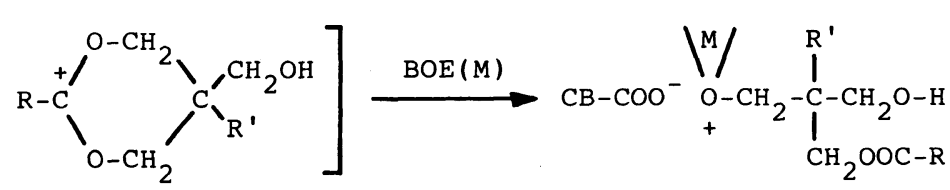

$$
\begin{aligned}
& \stackrel{\mathrm{nBOE}}{\longrightarrow}
\end{aligned}
$$

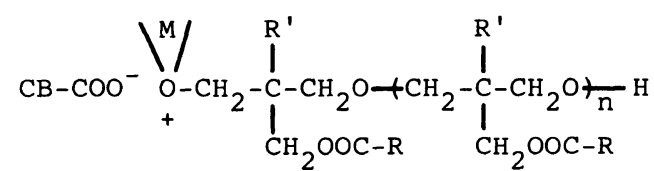


Grafting (Termination)

(1)

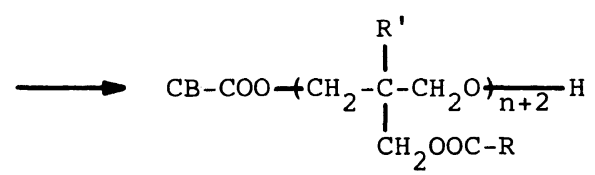

Formation of ungrafted Polymer (Chain Transfer)<smiles>[R]C(=O)OCC([R])(CO[C@@H]([R])[OH2+])CC([R])(C[B])C[O+]</smiles>

Table II. Cationic ring-opening isomerization polymerization of BOE (I) initiated by various kinds of carbon blacks ${ }^{\mathrm{a}}$

\begin{tabular}{|c|c|c|c|}
\hline \multirow{2}{*}{ Carbon black } & $\mathrm{COOH}$ & Conversion & $\begin{array}{l}\text { Percentage of } \\
\text { grafting }\end{array}$ \\
\hline & meq $\mathrm{g}^{-1}$ & $\%$ & $\%$ \\
\hline None & - & 3.8 & - \\
\hline FW 200 & 0.61 & 18.2 & 49.2 \\
\hline Carbolac 1 & 0.54 & 15.7 & 30.5 \\
\hline Neospectra II & 0.41 & 13.9 & 24.5 \\
\hline Philblack O & 0 & 4.2 & - \\
\hline KOH-FW 200 & 0 & 2.9 & - \\
\hline $\mathrm{CH}_{2} \mathrm{~N}_{2}$ - $\mathrm{FW} 200$ & 0 & 3.1 & - \\
\hline $\mathrm{HNO}_{3}$-Philblack O & 0.15 & 13.1 & $-^{\mathbf{b}}$ \\
\hline
\end{tabular}

${ }^{\text {a }}$ Carbon black, $0.30 \mathrm{~g}$; BOE (I), $0.02 \mathrm{~mol}$; temp, $130^{\circ} \mathrm{C}$; time, $4 \mathrm{~d}$.

b Percentage of grafting could not be determined because the resulting carbon black did not precipitate by centrifugation at $1.3 \times 10^{4} \mathrm{rpm}$ even after $10 \mathrm{~h}$ and passed through filter paper.

Cationic Polymerization of BOE Initiated by Acylium Perchlorate Group on Carbon Black In general, polymerization by an acylium cation was conducted without isolation of acylium perchlorate because the cation is very moisture sensitive. ${ }^{21,22}$ To confirm the initiation by the acylium perchlorate group on carbon black, the polymerization of I was carried out in the presence of $\mathrm{CB}-\mathrm{COCl}$ and silver perchlorate under several conditions. The results are summarized in Table III.

No difference in conversion between in the absence and presence of silver perchlorate and
Table III. Polymerization of BOE (I) in the presence of carbon black containing the acyl chloride group and silver perchlorate ${ }^{\mathrm{a}}$

\begin{tabular}{cccc}
\hline & $\mathrm{AgClO}_{4}$ & & \multicolumn{2}{c}{ Conversion } \\
\cline { 2 - 2 } Carbon black & $\mathrm{g}$ & & $\%$ \\
\hline- & - & & 3.8 \\
- & 0.20 & & 4.1 \\
Neospectra II-COCl & - & & 4.9 \\
Neospectra II-COCl & 0.20 & & 35.1 \\
\hline
\end{tabular}

a Pretreatment: carbon black, $0.30 \mathrm{~g}$; nitrobenzene, $5.0 \mathrm{ml}$; room temperature; time, $2 \mathrm{~h}$. Polymerization: BOE (I), $0.02 \mathrm{~mol}$; temp, $70^{\circ} \mathrm{C}$; time, $3 \mathrm{~d}$

between those of $\mathrm{CB}-\mathrm{COCl}$ was detected. Therefore, it seems that BOE was not polymerized by silver perchlorate or $\mathrm{CB}-\mathrm{COCl}$ alone. In the presence of $\mathrm{CB}-\mathrm{COCl}$ treated with silver perchlorate, however, the polymerization of $\mathbf{I}$ was initiated. Figure 4 shows the effect of temperature on the polymerization of $\mathbf{I}$ initiated by acylium perchlorate group on carbon black. The rate of polymerization was found to increase with rise in polymerization temperature.

All the ungrafted polymers obtained were viscous liquids and identified as the corresponding polyether containing ester groups in the side chain by IR and NMR.

\section{Proof of Grafting from Carbon Black}

To confirm the grafting from carbon black, the percentage of grafting of the polymer from 


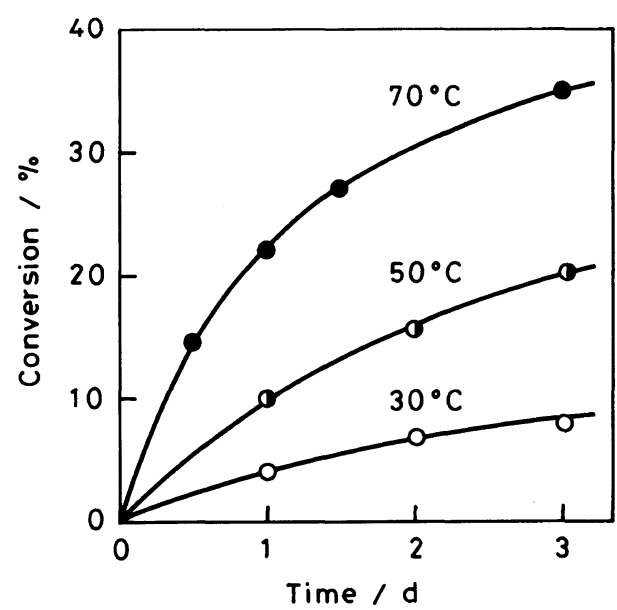

Figure 4. Effect of temperature on the cationic ringopening isomerization polymerization of BOE (I) initiated by acylium perchlorate group on carbon black: Pretreatment: Neospectra II-COCl, $0.30 \mathrm{~g}$; silver perchlorate, $0.20 \mathrm{~g}$; nitrobenzene, $5.0 \mathrm{ml}$; room temperature; time, $2 \mathrm{~h}$. Polymerization: BOE (I), $0.02 \mathrm{~mol}$.

carbon black was determined and the results are shown in Figure 5.

The percentage of grafting increased gradually as the polymerication proceeded and reached $80.2 \%$ after 3 days. This value is higher than that obtained in the polymerization initiated by carboxyl group on carbon black. The percentage of grafting was hardly affected by the polymerization temperature.

The cationic ring-opening polymerization of II was found to be also initiated by acylium perchlorate group on carbon black and the polymer formed was grafted from carbon black as shown in Figure 6.

Accordingly, it is concluded that the acylium perchlorate group introduced onto carbon black has ability to initiate the polymerization of BOE and the polymer formed was effectively grafted from carbon black.

Mechanism of Initiation and Grafting by Acylium Perchlorate Group on Carbon Black

The polymerization of BOE was probably initiated by the addition of acylium ion to one

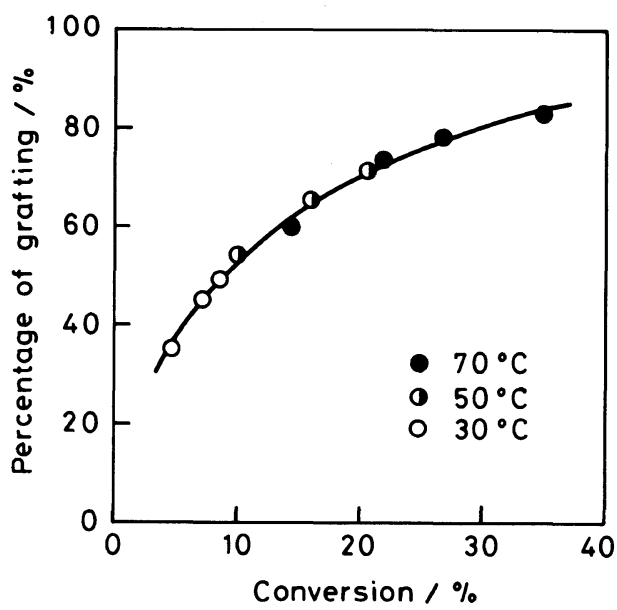

Figure 5. Relationship between the percentage of grafting and conversion. Polymerization conditions are given in Figure 4

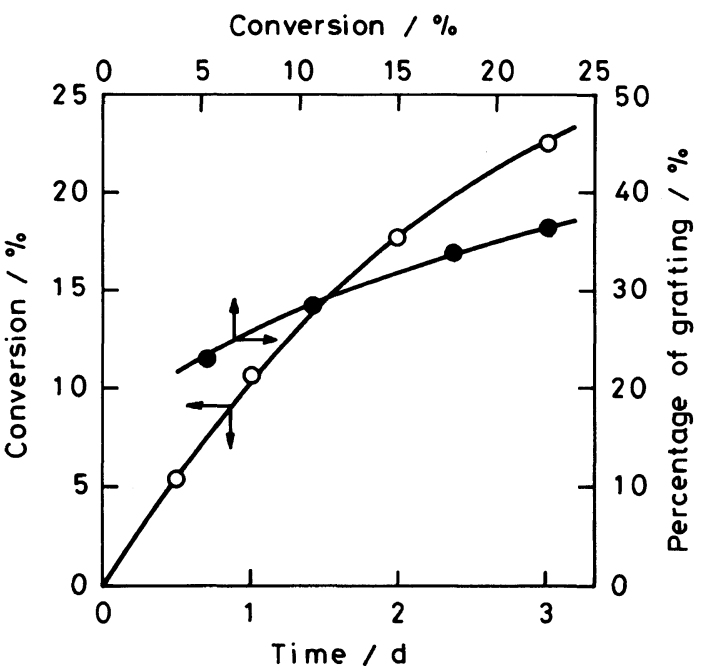

Figure 6. Cationic ring-opening isomerization polymerization of BOE (II) initiated by acylium perchlorate group on carbon black at $70^{\circ} \mathrm{C}$. Polymerization conditions are given in Figure 4.

of the oxygen atoms of the monomer. Then, propagation proceeds from the resulting oxonium ion with perchlorate anion as counter ion. Ungrafted polymer is also formed via the chain transfer of growing polymer. 
Initiation and Propagation (Grafting)

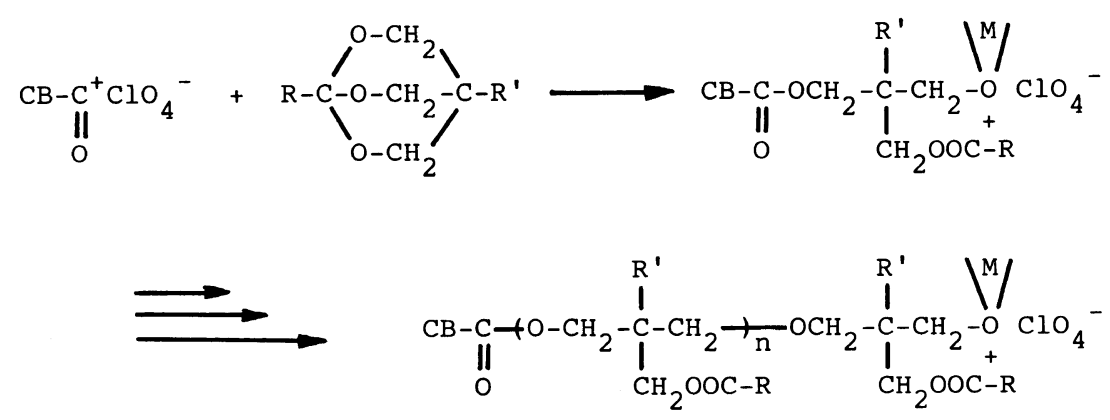

(2)

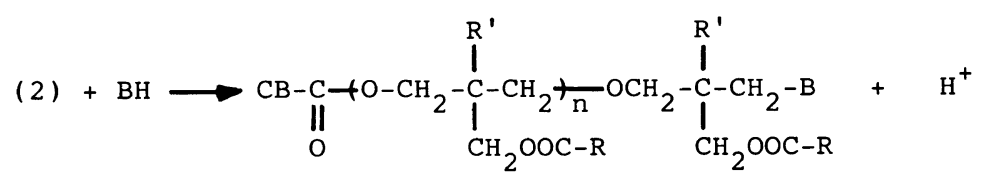

Formation of ungrafted Polymer

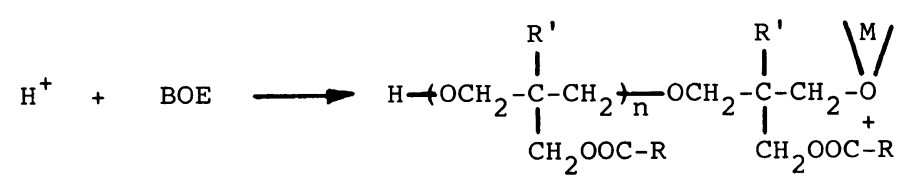

\section{REFERENCES}

1. K. Ohkita, N. Tsubokawa, M. Noda, and $\mathbf{M}$. Uchiyama, Carbon, 15, 194 (1977).

2. N. Tsubokawa, N. Takeda, and K. Kudoh, Nippon Kagaku Kaishi, 1264 (1980).

3. N. Tsubokawa, J. Polym. Sci., Polym. Lett. Ed., 18, 401 (1980).

4. N. Tsubokawa, N. Takeda, and A. Kanamaru, $J$. Polym. Sci., Polym. Lett. Ed., 18, 625 (1980).

5. N. Tsubokawa, N. Takeda, and T. Iwasa, Polym. J., 13, 1093 (1981).

6. N. Tsubokawa, S. Ohshima, Y. Sone, and T. Endo, J. Polym. Sci., Polym. Chem. Ed., 25, 935 (1987).

7. N. Tsubokawa, S. Ohshima, Y. Sone, and T. Endo, Polym. J., 18, 851 (1986).

8. N. Tsubokawa, J. Polym. Sci., Polym. Chem. Ed., 22, 1515 (1984).

9. N. Tsubokawa, J. Appl. Polym. Sci., 30, 2041 (1985).

10. N. Tsubokawa, H. Nunokawa, and Y. Sone, $J$. Macromol. Sci.-Chem., A23, 105 (1986).
11. N. Tsubokawa, J. Polym. Sci., Polym. Chem. Ed., 25, 1979 (1987).

12. T. Endo, K. Saigo, and W. J. Bailey, J. Polym. Sci., Polym. Lett. Ed., 18, 457 (1980).

13. K. Saigo and W. J. Bailey, J. Polym. Sci., Polym. Chem. Ed., 21, 1435 (1983).

14. H. Uno, T. Endo, and M. Okawara, J. Polym. Sci., Polym. Chem. Ed., 23, 63 (1985).

15. J. B. Donnet, Carbon, 20, 266 (1982).

16. M. L. Studebaker, E. W. D. Huffman, A. G. Wolfe, and L. G. Nabors, Ind. Eng. Chem., 48, 162 (1956).

17. K. Ohkita, N. Tsubokawa, K. Sekine, and T. Yamada, Nippon Gomu Kyokaishi, 47, 40 (1974).

18. D. Rivin, Rubber Chem. Technol., 36, 729 (1963).

19. N. Tsubokawa, Y. Jian, and Y. Sone, Polym. Bull., 16, 294 (1986).

20. Y. Yokoyama, A. B. Padias, E. A. Bratoeff, and H. K. Hall, Jr., Macromolecules, 15, 11 (1982).

21. W. R. Longworth and P. H. Plesch, Proc. Chem. Soc., 117 (1958).

22. P. Dreyfuss and J. P. Kennedy, J. Polym. Sci., Polym. Lett. Ed., 14, 135 (1976). 